\title{
PKM Pengembangan Kawasan Pertanian Hidroganik Padi "Bengkel Mimpi” Menggunakan Sumber Energi Mandiri Fotovoltaik
}

\author{
Hery Budiyanto ${ }^{1}$, Aries Boedi Setiawan ${ }^{2 *}$,Aris Siswati ${ }^{3}$ \\ ${ }^{1}$ Arsitektur, Universitas Merdeka Malang, Jl Puncak Jaya 28 Malang, Indonesia. \\ ${ }^{2}$ Teknik Elektro, Universitas Merdeka Malang, Jl. Taman Agung Malang, Indonesia. \\ ${ }^{3}$ Manajemen, Universitas Merdeka Malang, Jl. Terusan Raya Dieng 62-64 Malang, Indonesia. \\ *Correspondence: Aries Boedi Setiawan (aries@unmer.ac.id) \\ Received: 30 Juni 2021 - Revised: 01 Agustus 2021 - Accepted: 16 Agustus 2021
}

\begin{abstract}
Abstrak. Saat ini ada cara lain untuk memanfaatkan lahan sempit sebagai usaha untuk mengembangkan hasil pertanian, yaitu dengan cara bercocok tanam secara Hidroganik yaitu sistem budidaya organik dengan menanam padi pada tanah humus di dalam gelas plastik yang ditanam pada jajaran pipa paralon diatas kolam ikan, memadukan sistem hidro (sirkulasi air bernutrisi) dan sistem organik (tanpa pupuk kimia). Sumber nutrisi utama dari hidroganik ini diperoleh dari pupuk organik padat dan cair serta air kolam yang ditreatment sebagai nutrisi tanaman. Program Kemitraan Masyarakat (PKM) ini bertujuan untuk menangani permasalahan yang dialami oleh mitra pengabdian yaitu Pusat Pelatihan Pertanian dan Pedesaan Swadaya "Bengkel Mimpi" di Dusun Krajan Desa Kanigoro RT 33 RW 03 Kecamatan Pagelaran Kabupaten Malang yang melakukan budidaya padi secara hidroganik. Masalahnya adalah bagaimana mendapatkan sumber tenaga listrik alternatif agar pengeluaran keuangan untuk listrik yang selama ini hanya dari PLN dapat lebih dihemat/dikurangi, sehingga solusi dan target luaran yang dilaksanakan dalam mengatasi permasalahan tersebut berupa pembangkit listrik tenaga surya (PLTS) yang digunakan untuk menggerakkan 12 buah pompa air hidroganik dan 2 buah lampu penerangan jalan di kawasan "Bengkel Mimpi". Setelah melalui perhitungan teknis, dipasang 6 buah solar panel $100 \mathrm{wp}$ lengkap dengan bracket penyangga, 3 buah battery $100 \mathrm{AH}, 1$ buah solar charge controller, 1 buah inverter $3000 \mathrm{WA}, 12$ buah pompa air. Kelebihan dari PLTS ini adalah aspek desain bracket penyangga solar panel yang dibuat atraktif menyerupai bentuk bunga matahari. Hasil pengujian telah dilakukan dalam kondisi cerah PLTS ini menghasilkan 2.144 WattJam. Luaran PKM ini dapat dijadikan sebagai model sumber tenaga listrik alternative di desa-desa lain secara nasional terutama pada lahan-lahan pertanian hidroganik maupun hidroponik yang lokasinya jauh dari jaringan listrik PLN.
\end{abstract}

Kata kunci: hidroganik, padi, energi mandiri, fotovoltaik

Citation Format: Budiyanto, H., Setiawan, A.B. \& Siswati, A. (2021). PKM Pengembangan Kawasan Pertanian Hidroganik Padi "Bengkel Mimpi" Menggunakan Sumber Energi Mandiri Fotovoltaik. Prosiding Seminar Nasional Abdimas Ma Chung (SENAM), 257-265. 


\section{PENDAHULUAN}

Beras merupakan makanan pokok lebih dari $95 \%$ penduduk Indonesia. Selain itu, bercocok tanam padi juga telah menyediakan lapangan pekerjaan bagi sekitar 20 juta rumah petani di pedesaan, sehingga dari sisi ketahanan pangan nasional fungsinya menjadi amat penting dan strategis (Rusdiana \& Maesya, 2017). Oleh sebab itu ketersediaan beras harus selalu terjamin karena dapat menyebabkan kerawanan bila terjadi kekurangan stok. Pesatnya laju pertumbuhan penduduk sebesar 1,31\% per tahun (lebih dari 271 juta jiwa pada tahun 2020) (Pangestika \& Prihtanti, 2020) menyebabkan meningkatnya kebutuhan terhadap beras sementara pertumbuhan produksinya tidak sebanding dengan permintaan, bahkan cenderung melandai (levelling Off). Petani yang kehilangan lahan sawahnya mayoritas mengalami penurunan pendapatan. Hal ini dikarenakan tingkat pendidikan dan ketrampilan para petani yang terbatas atau tergolong rendah sehingga mereka tidak dapat mengakses pekerjaan formal (Dewi \& Rudiarto, 2013). Para petani biasanya menggunakan tanah untuk media tanam, namun seiring dengan perkembangan kota lahan pertanian banyak yang berubah menjadi lahan permukiman dan fasilitas kota lainnya sehingga lahan pertanian menjadi semakin sempit. Kekurangan lahan untuk budidaya pertanian padi saat ini telah menimbulkan inovasi kearah intensifikasi pemakaian lahan berupa sistem hidroponik (Sudarmo, 2018). Tanaman yang digunakan untuk budidaya hidroponik adalah tanaman yang cepat panen dan memiliki perakaran yang dangkal ${ }^{\mathrm{i}}$. Budidaya hidroponik alternatif yang memanfaatkan media organik dan pupuk organik yang dikenal dengan hidroganik (Putra et al., 2020), berasal dari kata "Hidro" dan "Organik" yang didefinisikan sebagai sistem budidaya organik dengan memadukan sistem hidro dan sistem organik. Sumber nutrisi utama dari hidroganik ini diperoleh dari pupuk organik padat dan cair serta air kolam yang di-treatment sebagai nutrisi tanaman (Udin, 2017).

Keuntungan cara bercocok tanam sistem hidroganik padi adalah: 1) Hasil dan kualitas tanaman lebih tinggi; 2) Lebih terbebas dari hama dan penyakit; 3) Penggunaan air dan pupuk lebih hemat; 4) Dapat untuk mengatasi masalah tanah; 5) Dapat untuk mengatasi masalah keterbatasan lahan (Budiyanto, Haris, Setiawan, et al., 2019). Sedangkan keunggulannya adalah: 1) Tidak perlu pengolahan tanah;2) Tidak perlu rotasi tanaman; 3) Hasil seragam; 4) Bersih 5) Hasil tinggi; 6) Tenaga kerja sedikit (efisien); 7) Lebih mudah dalam pemeliharaan; 8) Lebih mudah dalam mengganti tanaman baru; 9) Dapat merupakan tempat dan cara untuk memperbaiki mutu tanaman; 10) Tidak banyak 
gulma; 11) Pengendalian hama lebih mudah; 12) Tidak perlu penyemaian; 13) Lebih hemat bibit; 14) Perawatan mudah; 15) Tidak perlu irigasi; 16) Panen lebih mudah dan lebih maksimal; 17) Panen ikan; 18) Tidak membutuhkan air banyak; 19) Bisa dibuat disekitar rumah, di lahan kering, di atas bangunan dan halaman mall; 20) Panen yang dihasilkan lebih sehat karena tidak menggunak pupuk kimia dan pestisida kimia; 21) Dalam satu tahun bisa panen 4 kali. (Budiyanto, Haris, \& Boedi, 2019).

Kegiatan PKM ini berangkat dari adanya masalah sumber tenaga listrik yang merupakan salah satu kebutuhan dasar bagi pertanian padi pada kawasan pertanian hidroganik dan Pusat Pelatihan Pertanian dan Pedesaan Swadaya "Bengkel Mimpi" di Desa Kanigoro, Kecamatan Pagelaran, Kabupaten Malang, dimana terdapat 12 unit pertanian sistem hidroganik padi yang masing-masing unit membutuhkan pompa sirkulasi air. Selama ini tenaga listrik untuk menggerakkan pompa sirkulasi air berasal dari PLN sehingga cukup memberatkan bagi pengelola pertanian hidroganik padi "Bengkel Mimpi". Tujuan kegiatan PKM ini adalah mengatasi permasalahan beban biaya listrik pertanian hidroganik padi "Bengkel Mimpi" yang perlu sumber tenaga listrik alternatif agar pengeluaran keuangan untuk listrik yang selama ini hanya dari PLN dapat lebih dihemat/dikurangi.

\section{MASALAH}

Selama ini Bengkel Mimpi dalam mengelola tanaman padi maupun sayur secara hidroganik masih mengandalkan energi listrik PLN untuk menggerakkan pompa-pompa air di masing-masing unit hidroganik. Apabila aliran listrik padam maka pompa akan terhenti. Hal ini akan mempengaruhi kehidupan ikan yang selalu memerlukan air beroksigen. Sehingga memerlukan sumber energi listrik mandiri yang kontinyu selain listrik PLN. Solusi dan target luaran yang akan dilaksanakan dalam mengatasi permasalahan tersebut berupa pembangkit listrik tenaga surya (PLTS) untuk menggerakkan pompa air hidroganik dan lampu penerangan jalan di kawasan "Bengkel Mimpi”.

\section{TUJUAN}

Program Kemitraan Masyarakat (PKM) ini bertujuan untuk menangani permasalahan utama yang dialami oleh Pusat Pelatihan Pertanian dan Pedesaan Swadaya "Bengkel Mimpi” di Dusun Krajan Desa Kanigoro RT 33 RW 03 Kecamatan Pagelaran 
Kabupaten Malang yaitu bagaimana mendapatkan sumber tenaga listrik alternatif agar pengeluaran keuangan untuk listrik yang selama ini hanya dari PLN dapat lebih dihemat/dikurangi.

\section{METODE PELAKSANAAN}

Artikel ini merupakan hasil Program Kemitraan Masyarakat (PKM) yang merupakan penelitian tindakan (action research) yang menggunakan metode deskriptif kualitatif dengan studi kasus "Bengkel Mimpi”. Metode pelaksanaan meliputi 4 langkah, yaitu: a) Desain dan Perhitungan PLTS, b) Pemasangan PLTS, c) Penggunaan PLTS di "Bengkel Mimpi”, d) Evaluasi dan pelaporan kegiatan.

\section{HASIL DAN PEMBAHASAN}

\section{Diskusi}

PKM dimulai dengan diskusi antara Tim PKM dengan kelompok "Bengkel Mimpi" untuk memetakan permasalahan yang terjadi/dialami oleh kelompok. Hasil diskusi awal mengerucut pada penggunaan sumber listrik alternatif berupa Pembangkit Listrik Tenaga Surya (PLTS) untuk menjalankan pompa-pompa sirkulasi hidroganik (Budiyanto, Haris, Setiawan, et al., 2019). Langkah awal dilakukan perhitungan komponen-komponen PLTS (panel surya, baterai, solar controller, dan inverter). Dilanjutkan dengan pembahasan tentang desain yang inovatif terutama pada bracket panel suryanya.

\section{Desain dan Perhitungan}

Mengacu pada Suryani (Suryani et al., 2018) dan Basiri (Basiri, 2019) maka Desain Skematik Pertanian Hidroganik Padi dengan PLTS dapat dilihat pada gambar 1.

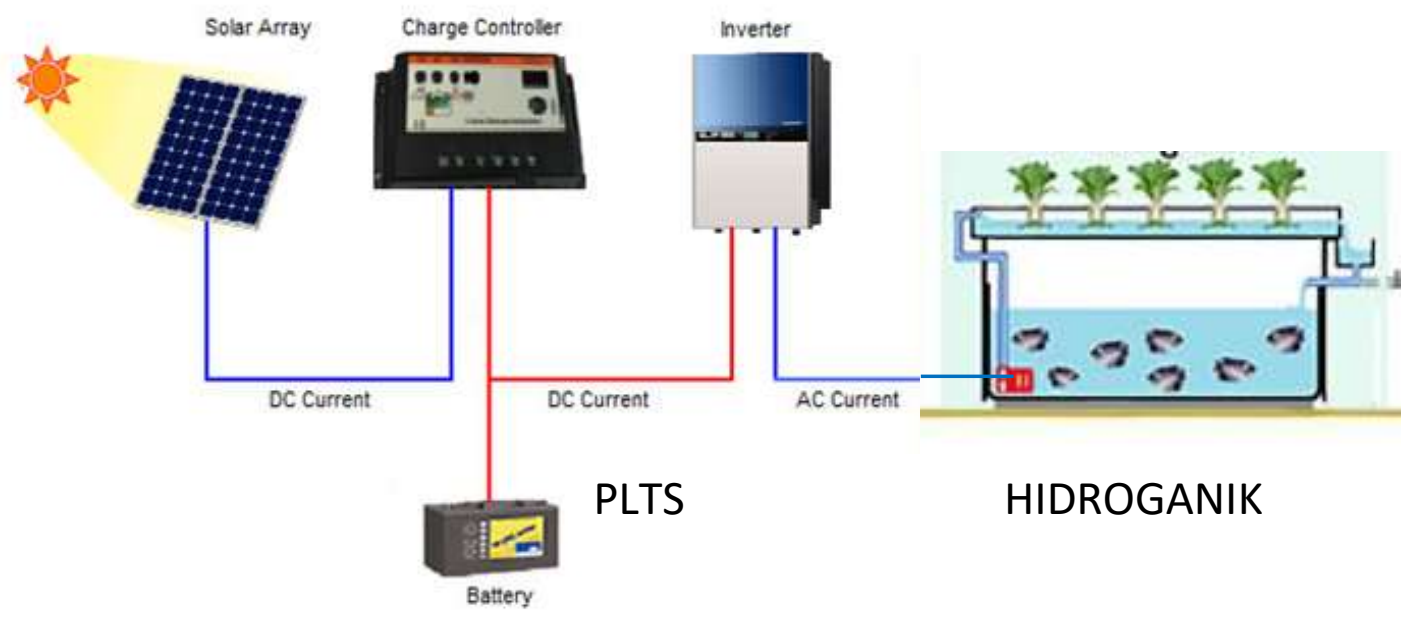

Gambar 1. Skematik PLTS untuk Pertanian Hidroganik dengan Energi Surya 
Pada skematik PLTS diperlihatkan sistem pengairan sebagai berikut: pengambilan air bersih menggunakan pompa air tandon bawah kemudian disalurkan ke kolam ikan hidroganik. Dari kolam hidroganik air dipompakan ke pipa-pipa paralon tempat menumbuhkan tanaman menggunakan pipa sirkulasi hidroganik. Sedangkan sumber tenaga listrik untuk kedua jenis pompa diambil dari inventer pada sistem pembangkit listrik tenaga surya.

Desain bracket panel surya dibuat dengan memperhatikan lingkungan pertanian sehingga bentuknya atraktif mengikuti bentuk bunga sebagaimana terlihat pada gambar 2 .

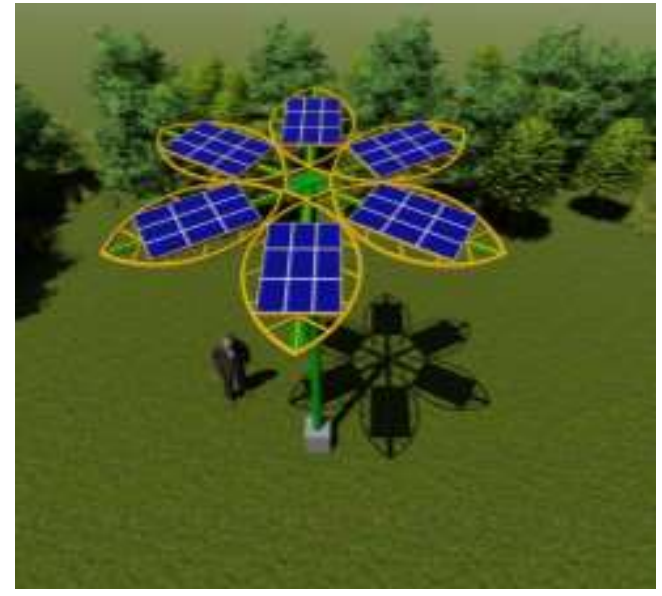

Gambar 2. Desain Bentuk Bracket Solar Panel

Perhitungan dilakukan untuk menjamin ketersediaan sumber listrik tenaga surya untuk menggerakkan minimal 12 pompa air $(12 \times 50$ Watt $=600$ Watt $)$. Mengacu pada rumusan yang dibuat oleh Suryani dkk (Suryani et al., 2018), maka didapat jumlah komponen yang dibutuhkan adalah: 6 buah solar panel 100 wp 12 V lengkap dengan bracket penyangga, 3 buah battery 100 AH 12 V, 1 buah solar charge controller 60 A, 1 buah inverter $3000 \mathrm{WA}$.

\section{Pemasangan PLTS}

Komponen PLTS yang dipasang terlebih dahulu adalah panel surya yang didukung oleh bracketnya, selanjutnya Pemasangan Box berisi Baterai, Solar Controller dan Inverter. Terakhir adalah menghubungkan antara panel surya dengan komponenkomponen PLTS lainnya. 

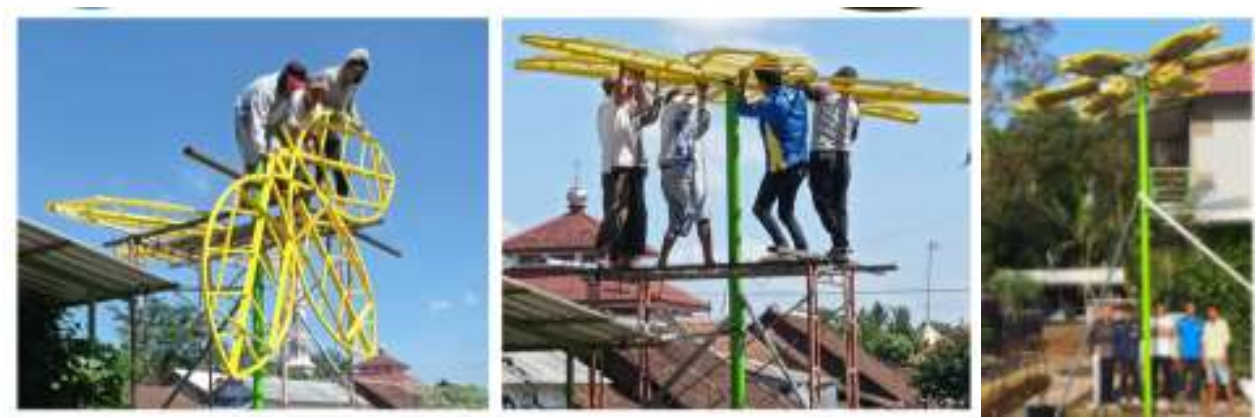

Gambar 3. Pemasangan Bracket Panel Surya

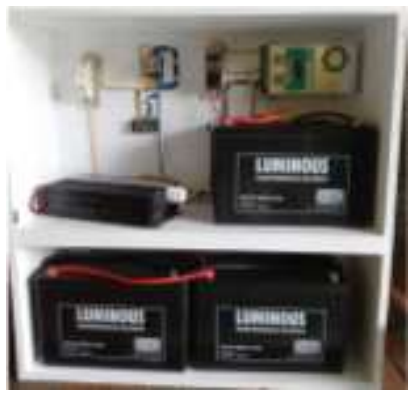

Gambar 4. Pemasangan Box berisi Baterai, Solar Controller dan Inverter

\section{Pengujian}

Pengujian kemampuan PLTS dilakukan setelah seluruh komponen PLTS terpasang. Pengujian dilakukan pada tanggal 6 Juli 2021 dari jam 06.00 hingga jam 17.30. dengan hasil sebagai berikut:

Tabel 1. Hasil Pengujian Kemampuan PLTS

\begin{tabular}{|r|r|r|r|r|r|r|}
\hline \multicolumn{1}{|c|}{ jam } & pv-volt & $\begin{array}{c}\text { pv- } \\
\text { ampere }\end{array}$ & pv-watt & $\begin{array}{c}\text { batt- } \\
\text { volt }\end{array}$ & $\begin{array}{c}\text { batt- } \\
\text { amp }\end{array}$ & $\begin{array}{c}\text { batt- } \\
\text { watt }\end{array}$ \\
\hline $6: 00$ & 12 & 0,66 & 7,92 & 12 & 0,74 & 8,88 \\
\hline $6: 30$ & 12 & 1,7 & 20,4 & 12 & 1,72 & 20,64 \\
\hline $7: 00$ & 12,1 & 3,68 & 44,528 & 12 & 2,99 & 35,88 \\
\hline $7: 30$ & 12,2 & 4,86 & 59,292 & 12,1 & 9,74 & 117,854 \\
\hline $8: 00$ & 12,5 & 10,75 & 134,375 & 12,2 & 10,02 & 122,244 \\
\hline $8: 30$ & 12,8 & 18,14 & 232,192 & 12,5 & 17,22 & 215,25 \\
\hline $9: 00$ & 13,1 & 19,27 & 252,437 & 13 & 22,84 & 296,92 \\
\hline $9: 30$ & 13,2 & 20,68 & 272,976 & 13,3 & 26,01 & 345,933 \\
\hline $10: 00$ & 13,4 & 24,61 & 329,774 & 13,3 & 24,39 & 324,387 \\
\hline $10: 30$ & 13,5 & 25,06 & 338,31 & 13,4 & 24,32 & 325,888 \\
\hline $11: 00$ & 14,9 & 24,54 & 365,646 & 13,4 & 24,01 & 321,734 \\
\hline $11: 30$ & 16,4 & 24,02 & 393,928 & 13,5 & 23,7 & 319,95 \\
\hline $0: 00$ & 17,4 & 18,52 & 322,248 & 14 & 29,18 & 408,52 \\
\hline $0: 30$ & 13,5 & 17,71 & 239,085 & 13,5 & 18,92 & 255,42 \\
\hline
\end{tabular}




\begin{tabular}{|r|r|r|r|r|r|r|}
\hline jam & pv-volt & $\begin{array}{c}\text { pv- } \\
\text { ampere }\end{array}$ & pv-watt & $\begin{array}{c}\text { batt- } \\
\text { volt }\end{array}$ & $\begin{array}{c}\text { batt- } \\
\text { amp }\end{array}$ & $\begin{array}{c}\text { batt- } \\
\text { watt }\end{array}$ \\
\hline $13: 00$ & 14 & 18,36 & 257,04 & 13,5 & 19,11 & 257,985 \\
\hline $13: 30$ & 13,6 & 15,33 & 208,488 & 13,5 & 17,25 & 232,875 \\
\hline $14: 00$ & 13,6 & 33,1 & 450,16 & 13,4 & 31,78 & 425,852 \\
\hline $14: 30$ & 13,2 & 8,96 & 118,272 & 13,3 & 9,38 & 124,754 \\
\hline $15: 00$ & 13,1 & 8,28 & 108,468 & 13 & 8,19 & 106,47 \\
\hline $15: 30$ & 12,9 & 5,49 & 70,821 & 12,8 & 5,7 & 72,96 \\
\hline $16: 00$ & 12,7 & 2,43 & 30,861 & 12,6 & 2,41 & 30,366 \\
\hline $16: 30$ & 12,5 & 2,54 & 31,75 & 12,6 & 1,35 & 17,01 \\
\hline $17: 00$ & 12,4 & 0,02 & 0,248 & 12,5 & 0,02 & 0,25 \\
\hline $17: 30$ & 4,9 & 0,01 & 0,049 & 12,5 & 0,01 & 0,125 \\
\hline & & & $\mathbf{2 1 4 4 , 6 3 4}$ & & & $\mathbf{2 1 9 4 , 0 7 4}$ \\
\hline
\end{tabular}

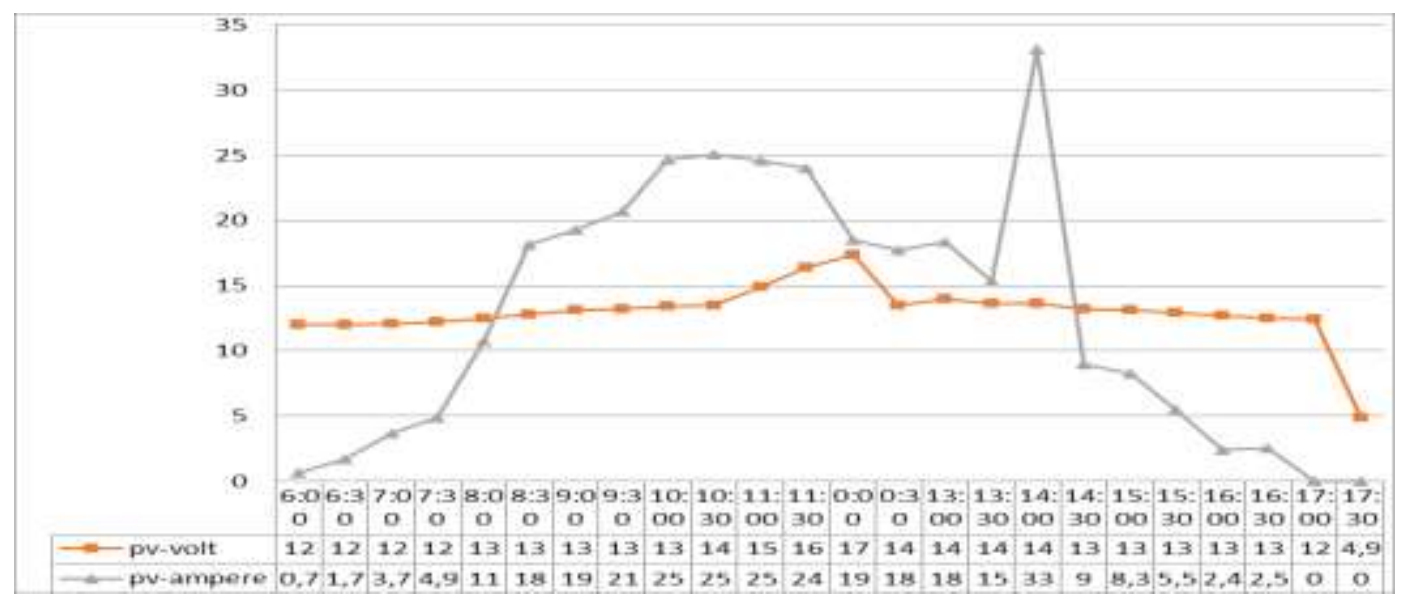

Gambar 5. Grafik Kemampuan PLTS

Hasil pengujian yang diperlihatkan pada Tabel 1 dan Gambar 5 menyatakan bahwa pengisian baterai efektif pada jam 7.30 hingga 16.00. Kemampuan daya PLTS yang didapan dalam 1 hari adalah 2.144 WattJam yang mampu untuk menggerakkan pompa air sirkulasi sejumlah 7 buah pompa selama 10 jam terus menerus.

Hasil pengujian tersebut menunjukkan bahwa PLTS dapat membantu meringankan biaya pembayaran listrik PLN sebesar $7 / 12 \times 100 \%=58 \%$ dari seluruh kebutuhan tenaga listrik untuk menggerakkan pompa sirkulasi hidroganik di "Bengkel Mimpi”

\section{Respon Masyarakat dan Stakehoders}

Sejak dipasangnya PLTS di kawasan "Bengkel Mimpi" maka berbagai tanggapan positif datang dari pihak-pihak, antara lain: Kepala Desa, Tokoh Masyarakat, Pemuda Desa, Pegiat LSM Malang Raya, Dinas Pertanian, dan Kementerian Pertanian yang 
menyaksikan desain serta kemampuan PLTS sehingga beberapa diantaranya berkeinginan untuk mengembangkannya di daerah lain baik di Malang Raya maupun Kabupaten/Kota lain.

\section{KESIMPULAN}

Pembangkit Listrik Tenaga Surya (PLTS) merupakan fasilitas yang sangat diperlukan oleh kelompok tani "Bengkel Mimpi" yang bergerak di bidang pertanian hidroganik padi, dimana diperlukan sumber listrik untuk menggerakkan pompa sirkulasi air hidroganik. Permasalahan sering terjadi ketika ada pemadaman listrik PLN dan beban daya bulanan listrik dari 12 buah pompa sirkulasi hidroganik cukup besar sehingga diperlukan sumber energi listrik selain PLN. Program Kemitraan Masyarakat (PKM) Pengembangan Kawasan Pertanian Hidroganik Padi "Bengkel Mimpi" Menggunakan Sumber Energi Mandiri Fotovoltaik telah berhasil menyelesaikan permasalahanpermasalahan tersebut, yaitu: 1) Pembuatan Desain PLTS dibuat atraktif dan menyesuaikan dengan lingkungan pertanian; 2) Meskipun kemampuan PLTS yang sudah terpasang baru mencapai 58\% dari kebutuhan sumber daya listrik yang ada, namun hasil tersebut telah banyak membantu kelompok "Bengkel Mimpi"; 3) Keberadaan PLTS di "Bengkel Mimpi" Desa Kanigoro Kecamatan Pagelaran Kabupaten Malang ini telah menjadi perhatian dari berbagai pihak yang mengunjungi "Bengkel Mimpi" sehingga ada kemungkinan untuk mengembangkannya di daerah lain.

\section{UCAPAN TERIMA KASIH}

Ucapan terima kasih ditujukan kepada:

1. Kementerian Pendidikan, Kebudayaan, Riset dan Teknologi yang telah menyediakan dana bagi pelaksanaan PKM tahun 2021;

2. Prodi Arsitektur, Prodi Elektro, Prodi Ekonomi Pembangunan, Lembaga Penelitian dan Pengabdian kepada Masyarakat Universitas Merdeka Malang, yang telah mendukung pelaksanaan pengabdian ini.

3. Komunitas "Bengkel Mimpi”, yang telah berpartisipasi dan sebagai Mitra pengabdian dalam Program Kemitraan Masyarakat. 


\section{DAFTAR PUSTAKA}

Basiri. (2019). Edukasi Pertanian Hidroganik Padi.

Budiyanto, H., Haris, M., \& Boedi, A. (2019). The Bamboo Greenhouse Technology for Hydroganic Crops with Independent Photovoltaic Electricity. International Journal of Science and Engineering Applications, 8, 517-521.

https://doi.org/10.7753/IJSEA0812.1004

Budiyanto, H., Haris, M., Setiawan, A. B., Sonalitha, E., \& Iqbal, M. (2019). Teknologi Greenhouse Hidroganik dengan Tenaga Listrik Mandiri. Seminar Nasional Infrastruktur Berkelanjutan Era Revolusi Industri 4.0, 2, 6.

https://ejournal.itn.ac.id/index.php/semsina/article/view/2220

Dewi, N. K., \& Rudiarto, I. (2013). Identifikasi Alih Fungsi Lahan Pertanian dan Kondisi Sosial Ekonomi Masyarakat Daerah Pinggiran di Kecamatan Gunungpati Kota Semarang. Jurnal Wilayah Dan Lingkungan, 1(2), 175. https://doi.org/10.14710/jwl.1.2.175-188

Pangestika, M., \& Prihtanti, T. M. (2020). Perbandingan Nilai Tukar Petani (Ntp) Antarsubsektor Pertanian Di Indonesia. AGRISAINTIFIKA: Jurnal Ilmu-Ilmu Pertanian, 4(1), 30. https://doi.org/10.32585/ags.v4i1.842

Putra, A. R. D., Mardiyani, S. A., \& Nurhidayati, N. (2020). Peran Vermikompos terhadap Morfofisiologi Kangkung Hidroganik. APutra, A. R. D., Mardiyani, S. A., \& Nurhidayati, N. (2020). Peran Vermikompos Terhadap Morfofisiologi Kangkung Hidroganik. Agrotechnology Research Journal, 4(2), 70.

Https://Doi.Org/10.20961/Agrotechresj.V4i2.41125grotechnology Research Journal, 4(2), 70. https://doi.org/10.20961/agrotechresj.v4i2.41125

Rusdiana, S., \& Maesya, A. (2017). Pertumbuhan Ekonomi Dan Kebutuhan Pangan Di Indonesia. Agriekonomika, 6(1). https://doi.org/10.21107/agriekonomika.v6i1.1795

Sudarmo, A. P. (2018). Pemanfaatan pertanian secara hidroponik untuk mengatasi keterbatasan lahan pertanian di Daerah Perkotaan. In A. Lilik Aslichati, Tutisiana, Adi Suryanto (Ed.), Seminar Nasional Pengabdian Kepada Masyarakt Universitas Terbuka (pp. 1-8). Universitas Terbuka.

Suryani, A., Fadhillah, A. P., Saichu, \& Mubarok, H. (2018). Instalasi Pembangkit Listrik Tenaga Surya Dos \& Don 'ts (B. Ramadhani (ed.); 1st ed.). Deutsche Gesellschaft für Internationale Zusammenarbeit (GIZ) $\mathrm{GmbH}$.

http://ebtke.esdm.go.id/post/2018/08/31/2007/buku.panduan.instalasi.pembangkit.listr k.tenaga.surya

Udin, A. (2017). BBPP Ketindan Kembangkan Sayuran Organik Dengan Hidroganik. BBPP Ketindan, 1. http://www.swadayaonline.com/artikel/377/BBPP-KetindanKembangkan-Sayuran-Organik-Dengan-Hidroganik

\section{(c) (i)}

(C) 2021 by authors. Content on this article is licensed under a Creative Commons Attribution 4.0 International license. (http://creativecommons.org/licenses/by/4.0/). 